\title{
Interdural cavernous sinus dermoid cyst in a child: case report
}

\author{
Flavio Giordano, MD,, Giacomo Peri, MD,1 Giacomo M. Bacci, MD, PhD, ${ }^{2}$ Massimo Basile, MD, ${ }^{3}$ \\ Azzurra Guerra, MD, ${ }^{4}$ Patrizia Bergonzini, MD, ${ }^{4}$ Anna Maria Buccoliero, MD, ${ }^{5}$ Barbara Spacca, MD, ${ }^{1}$ \\ Lorenzo lughetti, MD, PhD, ${ }^{4}$ PierArturo Donati, MD, ${ }^{1}$ and Lorenzo Genitori, MD1
}

\begin{abstract}
${ }^{1}$ Department of Neurosurgery, ${ }^{2}$ Neuro-ophthalmology Unit, ${ }^{3}$ Radiology Unit, and ${ }^{5}$ Pathology Unit, Anna Meyer Hospital, Firenze; and ${ }^{4}$ Department of Pediatrics, Ospedale Policlinico, University of Modena, Italy
\end{abstract}

Interdural dermoid cysts (DCs) of the cavernous sinus (CS), located between the outer (dural) and inner layer (membranous) of the CS lateral wall, are rare lesions in children. The authors report on a 5-year-old boy with third cranial nerve palsy and exophthalmos who underwent gross-total removal of an interdural DC of the right CS via a frontotemporal approach. The patient had a good outcome and no recurrence at the 12-month follow-up. To the best of the authors' knowledge this is the second pediatric case of interdural DC described in the literature.

https://thejns.org/doi/abs/10.3171/2016.9.PEDS1650

KEY WORDS dermoid cyst; interdural cavernous sinus tumors; ophthalmoplegia; skull base surgery; pterional approach; oncology

$\mathrm{D}$ ERMOID cysts (DCs) are extremely rare benign nonneoplastic tumors accounting for approximately $0.04 \%-0.06 \%$ of all intracranial lesions..$^{2,15,16,22-24}$ These cysts originate from ectopic inclusions of epithelial cells during closure of the neural tube, $3,5,8,27$ and are made of skin elements such as keratin, hair, sebum, epithelial debris, and a fatty liquid. $5,8,10,16,23$ They grow slowly by progressive desquamation within the cyst., ${ }^{3,23,24}$ Due to a common congenital origin they are often confused with epidermoid cysts, even though they are 4-9 times less frequent. ${ }^{15,16}$

Dermoid cysts are mostly infratentorial lesions and rarely occur in the supratentorial compartment; $5,15,16,27$ their preferred location is the suprasellar region. ${ }^{4,5,9}$ Supratentorial DCs are usually diagnosed in patients who are between 20 and 30 years old, , $, 16,20$ and are rarely located in the CS. $., 2,7,10,12,16,19-24,29$ El-Kalliny et al. ${ }^{14}$ have classified tumors of the CS lateral wall into 3 types: invasive from adjacent structures, interdural, and intracavernous. Interdural tumors are located inside the lateral wall of the CS between the outer dural layer and the inner membranous layer. According to this classification, pure interdural DCs, also called DCs of the lateral wall of the CS, ${ }^{19}$ are much more rare; only 6 cases are reported in the literature, 2,19,20,23,24 among which only 1 occurred in a pediatric patient. ${ }^{20}$

Clinical findings associated with DCs usually include epilepsy ${ }_{16,29}$ cranial nerve or other neural structure impairment caused by focal compression, ,7,16,20,22,24,29 and sometimes acute aseptic chemical meningitis due to spontaneous rupture. $8,10,12,21,29$

We report a new pediatric case of an interdural DC of the CS lateral wall that was successfully removed in a 5 -year-old boy, along with our 1-year follow-up findings. 


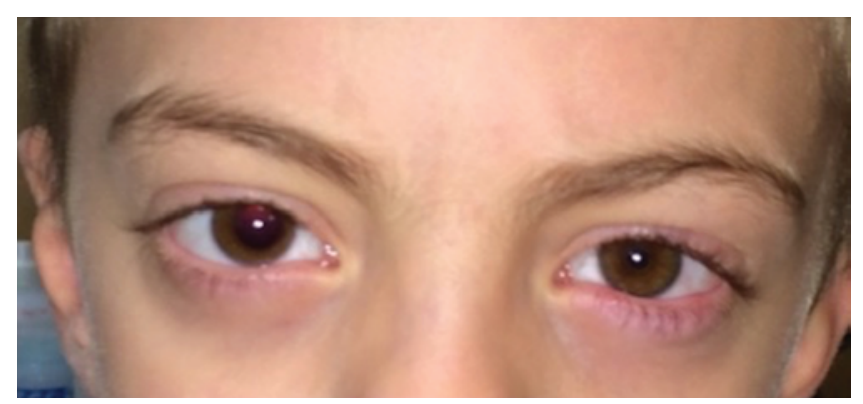

FIG. 1. Preoperative ocular findings. A right third cranial nerve paresis was present with slight right exophthalmos, upper eyelid ptosis, and anisocoria with right fixed mydriasis and absence of light pupillary reflex. Figure is available in color online only.

To the best of our knowledge this is the second pediatric interdural DC described in the literature.

\section{Case Report}

\section{History and Examination}

A previously healthy 5-year-old boy presented with a 1-year history of bilateral frontal headache, chronic fatigue, diplopia, ptosis, and swelling of the right eye. Neuro-ophthalmological examination revealed best corrected visual acuity of 20/20 in both eyes, normal color vision, and right third cranial nerve paresis, together with a right exophthalmos, crossed diplopia, upper-eyelid ptosis, and anisocoria with right fixed mydriasis and absence of light pupillary reflex; results of the anterior segment and fundus examination were unremarkable (Fig. 1). A cranial CT scan disclosed a low-density, well-defined, smooth, oval lesion in the region of the right CS; there was a slight hyperdense rim into the cyst wall, perhaps due to calcifications and a scalloping of the sphenoid bone (Fig. 2). The MR images revealed a well-circumscribed oval lesion with smooth contours inside the lateral wall of the right CS. The lesion was hypointense on T1-weighted images, with some hyperintense signal at its periphery, and it was hyperintense and heterogeneous on T2-weighted images. There was no enhancement on T1-weighted images obtained after gadolinium injection, except for a slight rim around the edges of the lesion. The lesion displaced the intracavernous internal carotid artery (ICA) medially, and diffusion-weighted imaging (DWI)
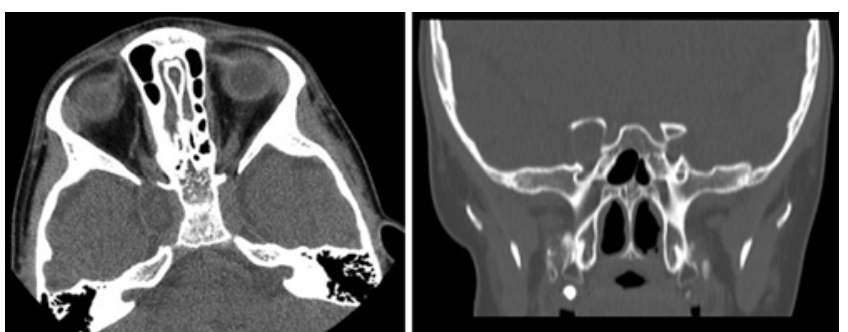

FIG. 2. Preoperative CT scans. In the axial section (left), the lesion appears to be located in the CS region with hypodense signal and to have a regular, oval shape; a hyperdense rim corresponds to some calcifications in the lesion capsule. In the coronal section (right), a scalloping of the lesser sphenoid wing and of anterior clinoid process is evident.
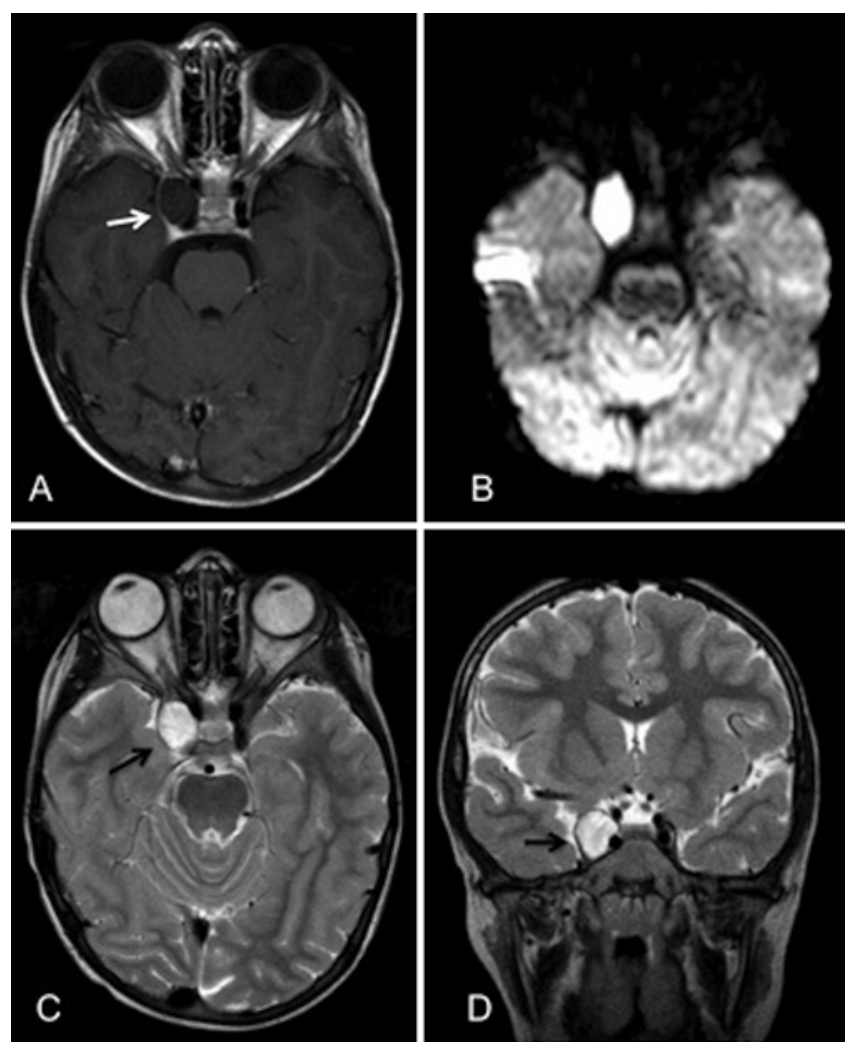

FIG. 3. Preoperative MR images. A T1-weighted scan obtained after gadolinium injection (A) shows a smooth, oval, hypointense lesion inside the lateral wall of the CS with a slight enhancement of the tumor capsule (white arrow). A DWI scan reveals a typical restricted proton diffusion within the lesion (B). T2-weighted scans show a hyperintense lesion with inhomogeneous areas inside the lateral wall of the CS in axial (C) and coronal (D) sections; the ICA is displaced medially, and the lateral wall of the CS is stretched and clearly visible (black arrows).

sequences revealed a restricted proton diffusion within the lesion (Fig. 3).

The differential diagnosis of the lesion included the following possibilities: DC of the lateral wall of the CS; arachnoid cyst; third, fourth, or fifth cranial nerve neurinoma; cystic glioma; or craniopharyngioma. The clinical and neuroradiological findings supported the first hypothesis - the diagnosis of DC of the lateral wall of the CS. Therefore, surgery was offered to the child's parents as the best treatment because the chance of expected symptomatic improvement was estimated to be higher than the chance of surgery-related morbidity. The child underwent surgical removal of the lesion after his parents gave informed consent according to our institutional code of ethics.

\section{Operation}

After induction of general anesthesia and endotracheal intubation, venous and arterial accesses were established. The patient was placed supine and the head was secured in a Mayfield clamp and rotated $30^{\circ}$ to the left and slightly extended, with the right shoulder lifted up. The head was coregistered to the Neuronavigation System (Treon Neuronavigation System; Medtronic, Inc.). A right frontotem- 


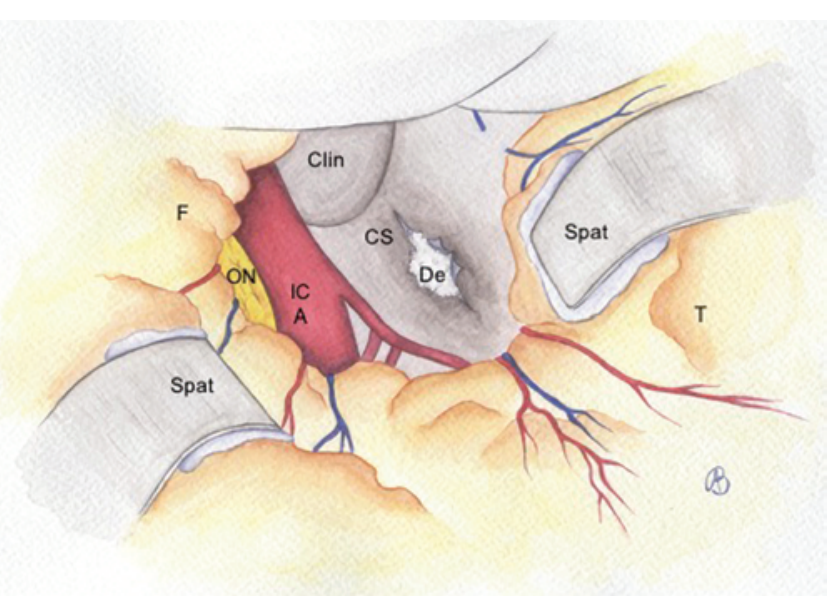

FIG. 4. Drawing of microsurgical intraoperative findings. $\mathrm{Clin}=$ anterior clinoid process; $\mathrm{De}=$ dermoid cyst; $\mathrm{F}=$ right frontal lobe; $\mathrm{ON}=$ optic nerve; Spat = spatula of self-retractor; $T=$ right temporal lobe. Copyright Beatrice A. Rossi. Published with permission. Figure is available in color online only.

poral craniotomy was performed after a curvilinear skin incision was made behind the hairline, separately cutting the temporal fascia and muscle to preserve the frontal branch of the facial nerve by retracting the fascia anteriorly and the muscle posteroinferiorly. The dura mater was opened with a standard C-shaped incision, and the arachnoid layer was microsurgically dissected to open the anterior half of the sylvian fissure by using a self-retractor. The right ICA and the right optic nerve were visualized, along with a whitish mass bulging through the lateral wall of the CS. The outer (meningeal) layer of the lateral wall was incised and opened in a stellate fashion over the most prominent part of the tumor, where no cranial nerves were identifiable at higher magnification and corresponding approximately to the Parkinson's triangle area (Fig. 4).

The mass was located inside the lateral wall of the CS and then was progressively removed in a piecemeal fashion from the inner side of the capsule with no significant bleeding; it showed a typical appearance consistent with greasy material and hair tufts. At the end of gross-total removal the cranial nerves became visible through the inner membranous layer of the CS lateral wall and through the inner DC capsule, which was preserved to avoid their injury. At the end of the excision, the surgical cavity was inspected with a microsurgical mirror to remove any remnant from inside. Hemostasis was achieved by packing the CS with oxidized cellulose, and the dura, the skull bone, and the skin wound were then closed in a standard fashion.

\section{Postoperative Course and Follow-Up}

The patient's postoperative recovery was uneventful, and a CT scan performed 1 day after surgery excluded surgical complications. The patient was discharged 4 days after surgery with no new neurological complaints. Histopathological examination of the surgical specimen confirmed that the tumor was a DC with abundant keratinic material; numerous foreign-body giant cells and occasional hairs were also seen (Fig. 5). At the 2-month follow-up the third cranial nerve impairment had partially recovered:

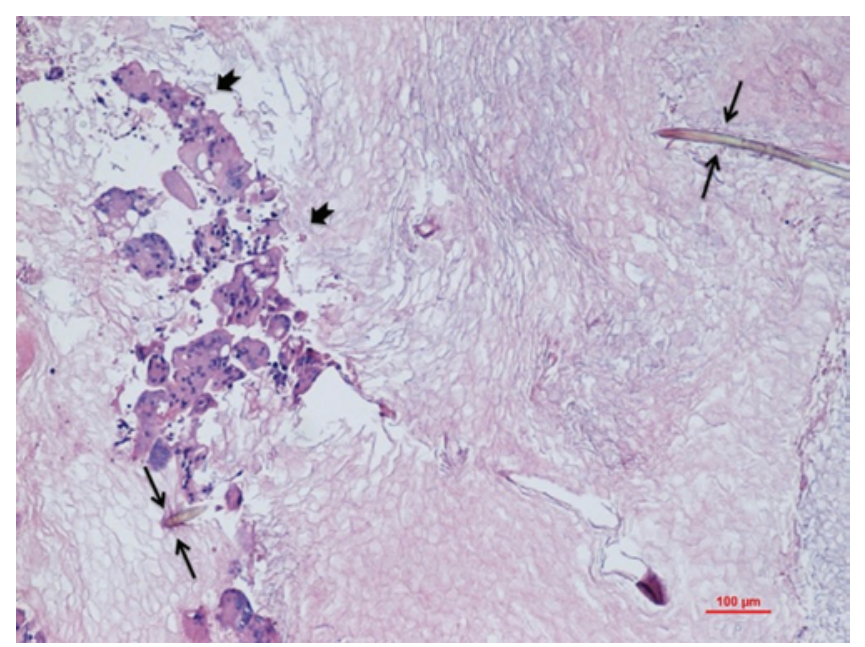

FIG. 5. Photomicrograph of an $\mathrm{H} \& \mathrm{E}$-stained section of the specimen obtained for histopathological examination showing abundant keratinic material, foreign-body giant cells (thick arrows), and occasional hairs (thin arrows). Figure is available in color online only.

the child no longer complained of diplopia; proptosis and ptosis had disappeared; and there was still a right mydriasis with a weak light pupillary reflex and limitation in eye adduction. Six months after surgery, an MRI study (Fig. 6) confirmed gross-total removal with decompression of CS neurovascular structures and without any tumor remnant or relapse; the preoperative hyperintense signal in FLAIR images completely disappeared after surgery (Fig. 7). At the last follow-up visit, 12 months after surgery, the child showed an almost complete recovery of eye movements and light pupillary reflex, and the right mydriasis had disappeared.

\section{Discussion}

We report the second pediatric case of an interdural DC of the lateral wall of the right CS in a 5-year-old boy with a good outcome 1 year after gross-total removal. Dermoid cysts are extremely rare nonneoplastic tumors account-
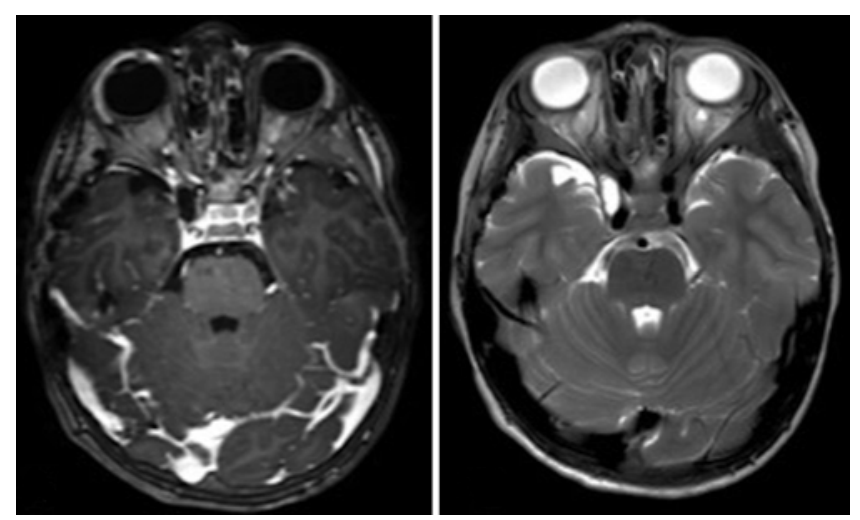

FIG. 6. Postoperative MR images obtained 6 months after surgery. A T1weighted image obtained after gadolinium enhancement showing that there is no further pathological enhancement (left). In a T2-weighted image, the debulking of the CS is clearly visible: the inhomogeneous signal is consistent with oxidized cellulose packed inside the CS (right). 

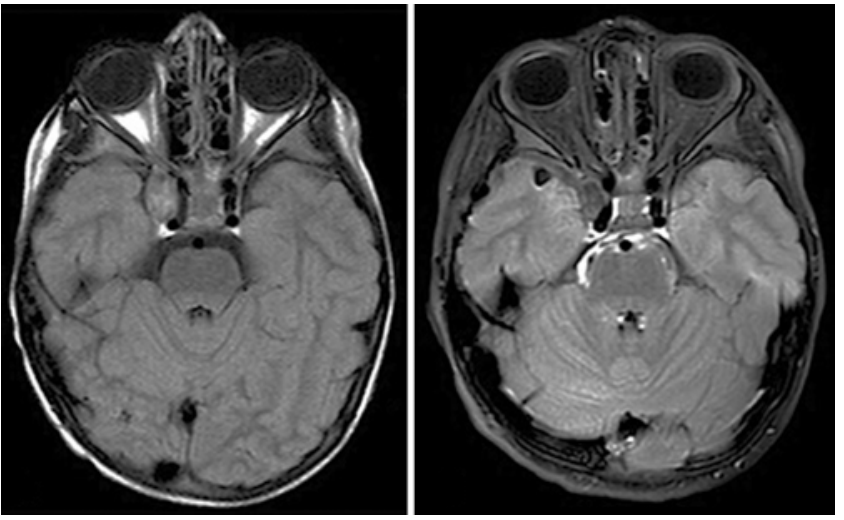

FIG. 7. Axial FLAIR MR images. Comparison between preoperative (left) and postoperative (right) images: the hyperintense signal present inside the lesion is no longer visible after surgery.

ing for approximately $0.04 \%-0.06 \%$ of all intracranial lesions, and are 3 to 10 times less frequent than epidermoid cysts. ${ }^{2,16,23,24}$ They are considered to originate from ectodermic remnants and are usually located near midline structures, with a peak age in the early decades (20-30 years of age). $4,5,16,23,24$ Their growth rate is slow, and the mean duration of symptoms ranges from 3 months to 6.9 years. ${ }^{5,16,23}$ Our patient was a 5-year-old boy with a history of disease lasting approximately 1 year before diagnosis. In 1993 North et al. ${ }^{20}$ reported on a 4-year-old boy harboring a DC of the lateral wall of the CS, and this was the only other pediatric case described in the literature before our experience.

Dermoid cysts are mostly located in the infratentorial compartment; when supratentorial, they are frequently in the suprasellar and parasellar, temporal and frontobasal regions. ${ }^{4,5,9,23}$ They may involve the CS, although pure DCs of the CS are rare: there are few and contradictory reports of DCs of the CS in the literature, and their relationship with the lateral wall of the CS is not always described in detail. $1,2,7,12,16,19-24,29$ From an anatomical point of view, the lateral wall of the CS is composed of 2 layers: the outer dural layer (dura propria) and the inner membranous layer, which are loosely attached and easily separable. . $^{13,14,25,26}$ The outer layer is thicker and more complete than the inner one, which is formed by the sheaths of the third, fourth, and fifth (ophthalmic and maxillary branches) cranial nerves, and by a reticular membrane connecting them; the inner layer divides the lateral wall with its contents from the venous channels of the CS. ${ }^{13,14,25,26}$ El-Kalliny et al. ${ }^{14}$ based their classification of CS lateral wall tumors according to the anatomy of the wall, distinguishing intracavernous tumors (Type I), interdural tumors (Type II), and invasive tumors (Type III) coming from adjacent structures. Interdural DCs of the CS were first defined by Nakagawa et al. ${ }^{19}$ in 1997; previous reports had generally described DCs of the lateral wall of the CS as extradural, intradural,

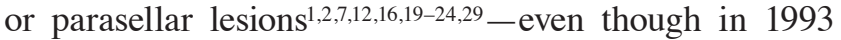
North et al. ${ }^{20}$ had reported a DC in a 4-year-old boy that was located "between the dural layers" of the CS lateral wall. Before the present case, a total of 6 patients harboring pure interdural DCs of the CS have been reported in the literature (Table 1). ${ }^{2,19,20,22-24}$
Clinical findings in DCs of the CS usually occur quite late, due to their slow growth pattern and the fact that symptoms are caused by direct focal compression of adjacent neural structures or sometimes by the acute rupture of the DC capsule leading to aseptic chemical meningitis and raised intracranial pressure. . $10,12,16,21,23,29$ The most frequent symptoms and signs may include headaches, oculomotor palsy, diplopia, visual loss and, more rarely, visual field defects, exophthalmos, hemiparesis, and raised intracranial pressure..$^{7,716,20,22-24,29}$ Dermoid cysts located in the lateral wall of the CS typically cause different degrees of oculomotor palsy, especially of the third and fourth cranial nerves, $2,16,19,20,22-24$ along with dysfunction of the ophthalmic and maxillary division of the fifth cranial nerve, both as trigeminal neuralgia and hypesthesia or impairment of temporal and masseter muscles. ${ }^{2,24}$ The pupillary muscles are not spared because the parasympathetic fibers are very sensitive to compression, and sometimes are affected earlier than oculomotor muscles. ${ }^{18,20}$ Perrini et al. ${ }^{22}$ reported a case of an interdural DC of the CS with isolated sixth cranial nerve palsy, whereas Rato and colleagues ${ }^{23}$ described a patient reporting only headaches. Our patient suffered from bilateral frontal headaches, diplopia, right ptosis, and right exophthalmos. His medical history was unremarkable. At neurological examination he showed a typical isolated right third cranial nerve impairment leading both to right ptosis and exotropia, and to fixed mydriasis due to loss of light pupillary reflex (Fig. 1). There was right exophthalmos, probably due to CS venous congestion, albeit no sign of papilledema was present at fundus examination. There was no dysfunction of either the fourth or sixth cranial nerves or of the trigeminal nerve.

Neuroradiological investigations are crucial for diagnosis and for planning the right surgical strategy. A CT scan usually shows an interdural DC as a low-density, oval lesion with the same signal for fat or CSF without contrast enhancement, ${ }^{2,11,17,28}$ although hyperdense DCs with capsular calcification in their wall have been described. ${ }^{6}$ On MR scans DCs usually appear as hyperintense and hypointense lesions in T1- and T2-weighted images, respectively, without peripheral edema; $;^{2,7,16,17,23,28}$ on T2weighted images the signal is frequently mixed and inhomogeneous, depending on the different proportions of DC elements. ${ }^{2,7,16,17,28}$ Use of FLAIR and DWI sequences may help in making the diagnosis of $\mathrm{DCs}^{10,16}$ by showing the cysts as hyperintense lesions and with typical restricted proton diffusion, respectively. The MR features suggesting CS interdural location of DCs include a smooth, oval, and regular shape and the medial displacement of the intracavernous ICA without its narrowing, as opposed to intracavernous and invasive CS tumors that usually encase the ICA. ${ }^{14,16,23,24}$ Differential diagnosis must consider trigeminal, oculomotor, and trochlear neurinomas; melanomas; metastatic tumors; cavernomas; arachnoid cysts; cystic gliomas; craniopharyngioma; and epidermoid cysts. ${ }^{2,14,23}$

The CT scan performed in the present case showed a typical, well-defined, oval lesion with hypodense signal within the region of the right CS; there was a slight hyperdense rim in the cyst wall due to calcifications and a scalloping of the lesser wing of the sphenoid bone and anterior 
TABLE 1. Literature review of interdural DCs of the lateral wall of the CS

\begin{tabular}{|c|c|c|c|c|c|c|c|c|}
\hline $\begin{array}{l}\text { Authors } \\
\& \text { Year }\end{array}$ & $\begin{array}{l}\text { Age } \\
\text { (yrs)/ } \\
\text { Sex }\end{array}$ & Localization & $\begin{array}{l}\text { Clinical } \\
\text { Findings }\end{array}$ & $\begin{array}{l}\text { Surgical } \\
\text { Approach }\end{array}$ & $\begin{array}{l}\text { Surgical } \\
\text { Removal }\end{array}$ & $\begin{array}{c}\text { FU, } \\
\text { Recurrence }\end{array}$ & Morbidity & Outcome \\
\hline $\begin{array}{l}\text { North et } \\
\text { al., } 1993\end{array}$ & $4 / \mathrm{M}$ & $\begin{array}{l}\text { Lat wall of CS, } \\
\text { interdural }\end{array}$ & Isolated CN III palsy & NA & Total & $\begin{array}{r}12 \text { mos, } \\
\text { none }\end{array}$ & $\begin{array}{l}\text { No compli- } \\
\text { cations }\end{array}$ & Full recovery \\
\hline $\begin{array}{l}\text { Nakagawa } \\
\text { et al., } \\
1997\end{array}$ & $19 / F$ & $\begin{array}{l}\text { Lat wall of rt } \\
\text { CS, inter- } \\
\text { dural }\end{array}$ & $\begin{array}{l}\text { HA, diplopia, ophthalmo- } \\
\text { plegia (CN III palsy), } \\
\text { slight anisocoria }\end{array}$ & $\begin{array}{l}\text { Frontotemporal } \\
\text { craniotomy }\end{array}$ & Total & NA & NA & $\begin{array}{l}\text { Partial recovery, improvement } \\
\text { of diplopia }\end{array}$ \\
\hline $\begin{array}{l}\text { Akdemir } \\
\text { et al., } \\
2004\end{array}$ & $18 / \mathrm{M}$ & $\begin{array}{l}\text { Lat wall of It CS, } \\
\text { interdural }\end{array}$ & $\begin{array}{l}\text { HA, diplopia, ophthal- } \\
\text { moplegia (CN III } \\
\text { palsy), blurred vision }\end{array}$ & $\begin{array}{l}\text { Frontoorbito- } \\
\text { zygomatic } \\
\text { craniotomy }\end{array}$ & Total & NA & $\begin{array}{l}\text { No compli- } \\
\text { cations }\end{array}$ & $\begin{array}{l}\text { Partial recovery, improvement } \\
\text { of diplopia \& ptosis; un- } \\
\text { changed ophthalmoplegia }\end{array}$ \\
\hline $\begin{array}{l}\text { Tun et al., } \\
2008\end{array}$ & $41 / F$ & $\begin{array}{l}\text { Lat wall of It CS, } \\
\text { interdural }\end{array}$ & $\begin{array}{l}\text { HA, diplopia, blurred } \\
\text { vision, CN III palsy }\end{array}$ & $\begin{array}{l}\text { Frontotemporal } \\
\text { craniotomy } \\
\text { plus zygomat- } \\
\text { ic osteotomy }\end{array}$ & $\begin{array}{l}\text { Gross- } \\
\text { total }\end{array}$ & $\begin{array}{r}12 \text { mos, } \\
\text { none }\end{array}$ & $\begin{array}{l}\text { No compli- } \\
\text { cations }\end{array}$ & $\begin{array}{l}\text { Partial recovery, improvement } \\
\text { of diplopia \& ptosis }\end{array}$ \\
\hline $\begin{array}{l}\text { Rato et al., } \\
2012\end{array}$ & $21 / F$ & $\begin{array}{l}\text { Lat wall of It CS, } \\
\text { interdural }\end{array}$ & $\mathrm{HA}$, blurred vision & $\begin{array}{l}\text { Frontotemporal } \\
\text { craniotomy }\end{array}$ & $\begin{array}{l}\text { Gross- } \\
\text { total }\end{array}$ & $\begin{array}{l}6 \text { mos, } \\
\text { none }\end{array}$ & $\begin{array}{l}\text { No compli- } \\
\text { cations }\end{array}$ & Full recovery \\
\hline $\begin{array}{l}\text { Perrini et } \\
\text { al., } 2013\end{array}$ & $37 / \mathrm{M}$ & $\begin{array}{l}\text { Lat wall of It CS, } \\
\text { interdural }\end{array}$ & Isolated CN VI palsy & $\begin{array}{c}\text { Frontotemporal } \\
\text { craniotomy }\end{array}$ & Total & $1 \mathrm{mo}$, none & $\begin{array}{l}\text { No compli- } \\
\text { cations }\end{array}$ & Full recovery \\
\hline $\begin{array}{l}\text { Present } \\
\text { study }\end{array}$ & $5 / \mathrm{M}$ & $\begin{array}{l}\text { Lat wall of rt } \\
\text { CS, inter- } \\
\text { dural }\end{array}$ & $\begin{array}{l}\text { HA, diplopia, CN III } \\
\text { palsy, exophthalmos }\end{array}$ & $\begin{array}{l}\text { Frontotemporal } \\
\text { craniotomy }\end{array}$ & $\begin{array}{l}\text { Gross- } \\
\text { total }\end{array}$ & $\begin{array}{r}12 \text { mos, } \\
\text { none }\end{array}$ & $\begin{array}{c}\text { No compli- } \\
\text { cations }\end{array}$ & $\begin{array}{l}\text { Partial recovery, disappear- } \\
\text { ance of diplopia \& exoph- } \\
\text { thalmos, improvement of } \\
\text { CN III palsy }\end{array}$ \\
\hline
\end{tabular}

$\mathrm{CN}=$ cranial nerve $; \mathrm{FU}=$ follow-up; $\mathrm{HA}=$ headache $; \mathrm{NA}=$ not available .

clinoid process, suggesting a long-lasting, slow growth of the lesion (Fig. 2). At MR investigation the lesion showed features consistent with the suspected diagnosis of an interdural DC of the CS: a well-circumscribed oval lesion with smooth contours inside the lateral wall of the right CS; a hypointense signal on T1-weighted images with some hyperintense signal at its periphery, and a hyperintense signal with heterogeneous areas on T2-weighted images; the lesion displaced the ICA, and there was no enhancement on T1-weighted images after gadolinium injection except for a slight rim around the lesion wall; on DW images there was the typical restricted proton diffusion (Fig. 3).

The 2 most used surgical approaches for DCs of the CS are intradural frontotemporal (pterional), ${ }^{19,22,23}$ frontotemporal plus zygomatic osteotomy, ${ }^{24}$ and frontoorbitozygomatic $^{2}$ (Table 1). The frontoorbitozygomatic route provides a wider exposure of the temporal lobe and of the CS region, reducing brain retraction, ${ }^{19,23,26}$ even though frontotemporal craniotomy can achieve enough working space and is less invasive, especially in children. On this basis we decided to perform a right frontotemporal craniotomy in our patient via an intradural approach to the CS region, which was easily exposed after a microsurgical opening of the anterior half of the sylvian fissure with minimal brain retraction by the self-retractor. The DC appeared as a whitish bulging of the CS lateral wall that was opened at the dome of the tumor, corresponding approximately to Parkinson's triangle (Fig. 4), and where no cranial nerves were recognizable at higher magnification.

Regarding the extent of resection, there is a controversy surrounding the risks and benefits of pursuing a radical re- moval of interdural DCs together with their capsule.,22-24,29 In their landmark series of 43 surgically treated patients with DCs and epidermoid cysts of the CS, Yaşargil et al. ${ }^{29}$ stated that radical removal of these lesions including the capsule increases the surgical morbidity significantly in terms of cranial nerve palsies, with no advantages for patients, given that the risk of DC relapse is quite low even after subtotal removal. ${ }^{2,16,23,24,29}$ Nevertheless, some authors have performed radical removal of DCs without reported morbidity. 2,19,20,22 Given the high risk of cranial nerve damage in the case of strict adherence between the capsule and neurovascular structures of the CS, we preferred to perform a gross-total removal of the DC, aiming to obtain maximal debulking of the CS as described by other authors. ${ }^{23,24}$ After opening the outer (dural) layer of the CS lateral wall at the dome of the tumor (Fig. 4), we carefully removed all the contents of the DC in a piecemeal fashion until the cranial nerves appeared through the DC inner wall and the inner (membranous) layer of the CS lateral wall. No attempt was made to dissect the inner capsule from the inner layer of the CS lateral wall. The postoperative recovery was uneventful.

Dermoid cysts have a thick capsule made of stratified squamous epithelium and contain dermal structures such as hair, hair follicles, sebaceous glands, teeth, or nails; they are usually filled with a yellowish-brown fluid as a result of sebaceous gland secretion and progressive epithelium desquamation. ${ }^{5,8,16,23,24}$ The cyst enlargement relies on the secretion and degeneration of dermal elements that progressively enlarge the capsule of the cyst, especially toward less resistant spaces like arachnoidal cisterns, sulci, or fissures,,$^{29}$ and its consistency depends on the ratio of 
various elements within the wall.5,9,10 A DC differs from teratomas and epidermoid cysts in that teratomas contain tissue from all 3 germinal layers and not only from the ectoderm as in DCs, whereas epidermoid cysts are usually filled with waxy concentric lamellae of cholesterol crystals. ${ }^{16}$ Histopathological examination of the surgical specimen revealed the typical findings of DCs, such as abundant keratinic material and occasional hairs that originated from the ectodermal layer; numerous foreign-body giant cells were also present (Fig. 5).

Regarding surgery-related morbidity, after the seminal work by Yaşargil et al., ${ }^{29}$ who described transient cranial nerve palsies and aseptic chemical meningitis, more recent reports have not reported neurological deterioration ${ }^{2,20,22-24}$ whatever the extent of removal, and have described improvement ${ }^{2,23,24}$ and sometimes complete neurological recovery ${ }^{19,20,22}$ in almost all patients. Our patient showed a significant improvement of third cranial nerve palsy 1 month after surgery and a reduction of exophthalmos. A postoperative MRI study performed 6 months after surgery confirmed gross-total removal of the DC and showed complete debulking of the CS lateral wall with its neurovascular structures (Fig. 6). The FLAIR images revealed a hypointense signal inside the surgical cavity as compared with the previous hyperintense lesion (Fig. 7); there was no sign of tumor remnant or relapse. At the last follow-up visit 12 months after surgery, diplopia and exophthalmos had completely disappeared, whereas there was still a slight third cranial nerve impairment at neurological examination.

\section{Conclusions}

Interdural DCs of the CS are rare intracranial lesions, especially in pediatric patients, but they should be considered in the differential diagnosis of CS tumors. Clinical findings consist of typical CS syndrome with third, fourth, fifth, and sixth cranial nerve impairments of various degrees. Neuroradiological workup enables us to recognize interdural DCs of the CS due to their typical appearance of smooth, oval lesions without contrast enhancement inside the lateral wall of the CS on MRI and with typical restricted proton diffusion on DWI sequences. The aim of surgery is to achieve gross-total removal while preserving the neurovascular structures, although some authors suggest a more aggressive resection including the DC capsule. In this report we have described a 5-year-old boy with an interdural DC who underwent gross-total removal through a frontotemporal craniotomy, who had a favorable outcome and no tumor recurrence at the 1-year follow-up. To the best of our knowledge this is the second pediatric case of interdural DC of the CS reported in the literature.

\section{References}

1. Abdelouafi A, Ousehal A, Gharbi A, Ait Benali S, El Kamar A, Kadiri R: [Cavernous sinus dermoid cyst with unusual parapharyngeal development.] J Neuroradiol 27:140-143, $2000(\mathrm{Fr})$

2. Akdemir G, Dağlioğlu E, Ergüngör MF: Dermoid lesion of the cavernous sinus: case report and review of the literature. Neurosurg Rev 27:294-298, 2004
3. Alvord EC Jr: Growth rates of epidermoid tumors. Ann Neurol 2:367-370, 1977

4. Arseni C, Dănăilă L, Constantinescu AI, Carp N, Decu P: Cerebral dermoid tumours. Neurochirurgia (Stuttg) 19:104-114, 1976

5. Baxter JW, Netsky MGF: Epidermoid and dermoid tumors: pathology, in Wilkins RH, Rengachary SS (eds): Neurosurgery. New York: McGraw-Hill, 1985, pp 655-661

6. Caldarelli M, Colosimo C, Di Rocco C: Intra-axial dermoid/ epidermoid tumors of the brainstem in children. Surg Neurol 56:97-105, 2001

7. Chen YF, Liu HM, Tu YK: Dermoid cyst as a dumbbellshaped tumour of the cavernous sinus. Pediatr Radiol 33:72, 2003

8. Cohen JE, Abdallah JA, Garrote M: Massive rupture of suprasellar dermoid cyst into ventricles. Case illustration. J Neurosurg 87:963, 1997

9. Conley FK: Epidermoid and dermoid tumors: clinical features and surgical management, in Wilkins RH, Rengachary SS (eds): Neurosurgery. New York: McGraw-Hill, 1985, pp 668-673

10. Dange N, Mahore A, Goel A: Ruptured giant dermoid cyst of the cavernous sinus. J Clin Neurosci 17:1056-1058, 2010

11. Davidson HD, Ouchi T, Steiner RE: NMR imaging of congenital intracranial germinal layer neoplasms. Neuroradiology 27:301-303, 1985

12. DeMonte F, al-Mefty O: Ruptured dermoid tumor of the cavernous sinus associated with the syndrome of fat embolism. Case report. J Neurosurg 77:312-315, 1992

13. Dolenc VV: Anatomy and Surgery of the Cavernous Sinus. Vienna: Springer, 1989, pp 269-341

14. el-Kalliny M, van Loveren H, Keller JT, Tew JM Jr: Tumors of the lateral wall of the cavernous sinus. J Neurosurg 77:508-514, 1992

15. Guidetti B, Gagliardi FM: Epidermoid and dermoid cysts. Clinical evaluation and late surgical results. J Neurosurg 47:12-18, 1977

16. Lunardi P, Missori P: Supratentorial dermoid cysts. J Neurosurg 75:262-266, 1991

17. Messori A, Polonara G, Serio A, Gambelli E, Salvolini U: Expanding experience with spontaneous dermoid rupture in the MRI era: diagnosis and follow-up. Eur J Radiol 43:1927, 2002

18. Miller NR: Topical diagnosis of neuropathic ocular motility disorders, in Miller NR (ed): Walsh and Hoyt's Clinical Neuro-Ophthalmology, ed 4. Baltimore: Williams \& Wilkins, 1985, pp 669-670

19. Nakagawa K, Ohno K, Nojiri T, Hirakawa K: [Interdural dermoid cyst of the cavernous sinus presenting with oculomotor palsy: case report.] No Shinkei Geka 25:847-851, 1997 (Jpn)

20. North KN, Antony JH, Johnston IH: Dermoid of cavernous sinus resulting in isolated oculomotor nerve palsy. Pediatr Neurol 9:221-223, 1993

21. Paik SC, Kim CH, Cheong JH, Kim JM: A ruptured dermoid cyst of the cavernous sinus extending into the posterior fossa. J Korean Neurosurg Soc 57:364-366, 2015

22. Perrini P, Di Russo P, Iannelli A: Dermoid cyst of the lateral wall of the cavernous sinus presenting with isolated abducens nerve palsy. Acta Neurochir (Wien) 155:741-742, 2013

23. Rato RM, Pappamikail LB, Ratilal BO, Luiz CA: Dermoid tumor of the lateral wall of the cavernous sinus. Surg Neurol Int 3:10, 2012

24. Tun K, Celikmez RC, Okutan O, Gurcan O, Beskonakli E: Dermoid tumour of the lateral wall of the cavernous sinus. $\mathbf{J}$ Clin Neurosci 15:820-823, 2008

25. Umansky F, Nathan H: The lateral wall of the cavernous sinus. With special reference to the nerves related to it. J Neurosurg 56:228-234, 1982

26. van Loveren HR, Keller JT, el-Kalliny M, Scodary DJ, Tew 
JM Jr: The Dolenc technique for cavernous sinus exploration (cadaveric prosection). Technical note. J Neurosurg 74:837844, 1991

27. Walker ML, Petronio M: Posterior fossa tumors: dermoid tumors, in Ellenbogen RG, Rengachary SS (eds): Principles of Neurosurgery, ed 2. Amsterdam: Mosby-Elsevier, 2005, pp 548-549

28. Wilms G, Casselman J, Demaerel P, Plets C, De Haene I, Baert AL: CT and MRI of ruptured intracranial dermoids. Neuroradiology 33:149-151, 1991

29. Yaşargil MG, Abernathey CD, Sarioglu AC: Microneurosurgical treatment of intracranial dermoid and epidermoid tumors. Neurosurgery 24:561-567, 1989

\section{Disclosures}

The authors report no conflict of interest concerning the materi- als or methods used in this study or the findings specified in this paper.

\section{Author Contributions}

Conception and design: Giordano. Acquisition of data: Giordano, Peri, Bacci, Basile, Guerra, Bergonzini, Buccoliero, Spacca, Iughetti. Analysis and interpretation of data: Giordano, Spacca. Drafting the article: Giordano, Spacca, Donati. Critically revising the article: Giordano, Spacca. Reviewed submitted version of manuscript: Giordano. Approved the final version of the manuscript on behalf of all authors: Giordano. Study supervision: Giordano, Genitori.

\section{Correspondence}

Flavio Giordano, Department of Neurosurgery, Anna Meyer Hospital, Viale Pieraccini 24, Firenze 50139, Italy. email: flavio. giordano@meyer.it. 